\title{
Marketing etnográfico
}

etnografia pode oferecer ao marketing um rico instrumental para o mapeamento do universo simbólico edas práticas de consumo. Sua eficiência será maior se utilizada segundo os pressupostos teóricos emetodológicos definidos pela antropologia, bastante diversos daqueles da pesquisa tradicional. Conduzida por pesquisadores sem formação adequada, a pesquisa de campo édesperdício de tempo, de dinheiro e de expectativas.

por Lívia Barbosa UFF

As freqüentes reportagens encontradas em publicações ligadas ao mundo dos negócios atestam: a etnografia está se tornando popular na área de marketing. $\mathrm{N}$ em todos se lembram, porém, de que ela é uma metodologia sofisticada e consumidora de tempo, e usá-la de maneira inadequada é gastar dinheiro à toa e desmoral izar uma ferramenta que tem muito a oferecer a qualquer pessoa interessada em marketing e em consumo.

O uso da etnografia acompanha as transformações que vêm ocorrendo na metodologia da pesquisa demercado desde a década de 1980. Há uma diminuição da ênfase em dados quantitativos e um interesse crescente por informações 
de cunho mais qual itativo. Essa mudança baseia-se nos evidentes limites da abordagem economicista na explicação do consumo e do comportamento do consumidor em um mundo cada dia mais complexo e inter-relacionado.

A etnografia. A etnografia consisteno processo de observar, participar e entrevistar o "nativo" em suas condições reais de existência. Ela abre espaço para a compreensão e explicação dos diferentes valores que estão por trás das práticas de consumo e dos papéis, funções e significados mutáveis a que são submetidos os produtos e serviços no momento em que saem da loja na mão dos consumidores e penetram em seu mundo cotidiano.

\section{O marketing etnográfico faz uso}

\section{de princípios teóricos oriundos da}

\section{antropologia que contrastam com os do}

\section{marketing tradicional tanto nos aspectos}

\section{teóricos como nos metodológicos.}

A etnografia oferece ao marketing a consciência da importância da compreensão da lógica e dos valores atribuídos aos produtos e serviços, aos novos usos que lhes são conferidos e às práticas a que estão submetidos, e mostra como tudo isso encontra-se inserido na vida cotidiana dos consumidores. Dados desse tipo, porém, são obtidos quando a etnografia éutilizada segundo determinad os parâmetros teóricos emetodológicos. Faz-se necessário, portanto, conhecer al guns desses pressupostos.

Metodologia. A realidade social tem uma natureza dupla. É composta pelo mundo material que nos rodeia e pelos instrumentos simbólicos por meio dos quais os seres humanos atribuem sentido a este mundo material. Pessoas, objetos, relações e acontecimentos fazem parte da vida cotidiana e da "realidade" apenas quando inseridos em um sistema de valores e significados.

Esses valores e significados são atribuídos pelo sistema classificatório e pelas estruturas simbólicas da mente humana. Os antropólogos fazem trabalho de campo porque tal metodol ogia os ajuda a perceber e mapear os diferentes princípios, lógicas e significados por meio dos quais as pessoas organizam a "realidade" em que vivem. 0 real significado de "ouvir" os consumidores é - ou deveria ser - mapear esses processos cognitivos inconscientes e automáticos - não apenas os "desejos" - por novos produtos e serviços.

Quando a observação direta do trabalho de campo é combinada a entrevistas em profundidade, a informação é enriquecida com o "ponto de vista nativo" sobre as práticas, as lógicas e os valores observados e o tom emocional (ethos) que envolve a situação. 0 antropólogo tem a oportunidade de olhar a realidade de um grupo de pessoas por meio das categorias que elas utilizam para organizarem o próprio mundo.

0 mapeamento de categorias é uma das partes da etnografia. Entretanto, se quisermos fazer um trabal ho que permita entender o significado do fluxo da ação social - "aquilo que está sendo dito" pelos atos ou pelo discurso -, temos de ir além. Temos de saber como esse sistema classificatório é apropriado no fluxo da vida social por diferentes atores, em diversos contextos e fases de suas vidas, a que fins eles são postos e quais as disputas simbólicas que se estabelecem ao redor deles. 0 universo daquilo que denominamos de "cultura" não é homogêneo. É polissêmico (comporta vários sentidos) e polifônico (tem várias vozes), para usar dois termos tão ao gosto da antropologia pós-moderna. Portanto, o trabalho etnográfico é de contextualização do significado, de construção de hierarquias de sentido para diferentes grupos em diferentes momentos.

O utras exigências metodológicas são necessárias quando estamos trabal hando na nossa própria sociedade, na qual tudo nos parece familiar. Deve ser adotada uma atitude de distanciamento, de "estranhamento". Estranhar significa olhar com novos olhos aquilo que nos passava inteiramente despercebido, procurar a lógica e o significado por trás da prática automática e inconsciente, olhar o mundo da cultura material que nos é tão "familiar" como se ele pertencesse a uma 
civilização desconhecida. 0 pesquisador deve estar consciente dos objetivos da etnografia e saber como a informação sociocultural produzida pode ser relacionada com o consumo, gerando novas oportunidades de mercado, novos produtos e novas formas de contato com o consumidor.

Inúmeras vezes o trabalho de campo é exercido por pesquisadores que pouco ou nada sabem sobre por que estão ali, e menos sobre o que fazer com os dad os coletados. Mais ainda: como faz pesquisas qualitativas há muito tempo, esse tipo de pesquisador julgase habilitado a fazer também etnografia.

Uma das armadilhas mais comuns da visão etnocêntrica éa imposição de uma classificação a priori sobre o grupo a ser estudado, a partir das experiências sociais do pesquisador. Um exemplo clássico éa atribuição da categoria "pobre" a determinados grupos, que nas pesquisas de mercado são referidos como consumidores $C$ eD. Pobreza éum conceito relativo, que depende do contexto e pode ser definido de diversas maneiras. Como pesquisadores de mercado e profissionais demarketing são, em maioria, oriundos das classes médias e altas da sociedade brasileira e habitam o eixo sul do Brasil, tomam a carência material como elemento definidor dos segmentos C e D.

Examinando-se as gravações das entrevistas e a forma de coleta de dados de muitas das pesquisas realizadas por pesquisadores que não estão devidamente preparados, percebe-se claramente 0 choque de percepções entre pesquisadores e "nativos".

Testemunhei, como consultora, uma pesquisa levada a cabo por uma empresa multinacional, no Nordeste, com mulheres das classes $C$ e D. Os pesquisadores, todos de São Paulo, tentavam impor a categoria "pobre" sobre as mulheres, quea todo tempo recusavam o rótulo. Q uando indicavam a carência material que, segundo eles, caracterizava a vida delas, estas apontavam al guém mais pobre. As mulheres assumiam-se como pobres apenas quando a situação podia ser compensada com uma posição mais alta em um sistema de classificação social e moral. "Sou pobre, mas honesta" e "sou rica da benção divina" foram e são al gumas das lógicas compensatórias utilizadas por esses segmentos.

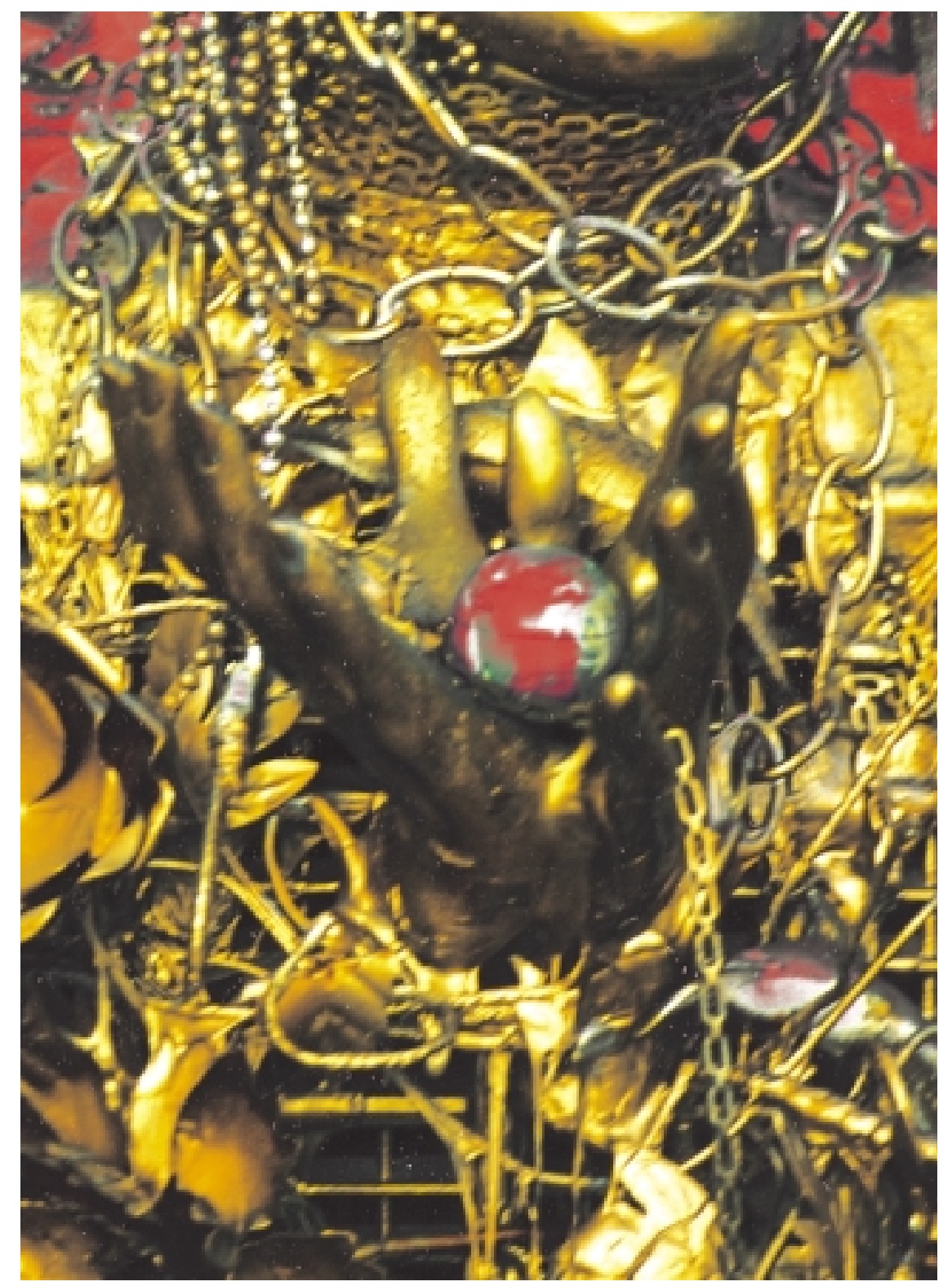


É difícil avaliar o quanto esses equívocos metodológicos afetam os dados e suas interpretações. Mas certamente os pesquisad ores perdem excelentes oportunidades para entender o consumidor de modo mais abrangente.

Como no caso das mulheres nordestinas, as perdas são às vezes óbvias. Para os pesquisadores, o principal critério para definir aquele grupo de consumidoras era a "pobreza"; para elas, porém, qual seria o principal critério para defini-las? Se elas recusavam o rótulo de "pobres" e apenas 0 admitiam em determinados contextos, qual era o significado atribuído à pobreza e como ele era interpretado em diferentes circunstâncias? Como a carência material era compreendida e como ela afetava as hierarquias de compra e de consumo? Essas são algumas das importantes questões inteiramente ignoradas pelo despreparo dos pesquisadores.

Embora possam ser neutralizadas com um melhor treinamento das equipes, essas deficiências permanecerão presentes enquanto os pesquisadores ignorarem os pressupostos metodológicos do trabalho de campo antropológico. N ão é suficiente "estar lá" e "observar" formas "exóticas" de vida, diferentes daquelas a que estão acostumados. É fundamental saber por que é importante estar lá, que tipo de dado a observação direta oferece, qual é a natureza da realidade social e por que observá-la diretamente pode produzir conhecimento diferenciado em relação às metodologias tradicionais.
Princípios etnográficos. 0 marketing etnográfico faz uso de princípios teóricos oriundos da antropologia quecontrastam com os do marketing tradicional em várias dimensões (ver Quadro).

Em primeiro lugar, o marketing etnográfico rejeita tratar produtos e serviços sem relacioná-los ao contexto em que se acham inseridos. Produtos e serviços encontram-se inseridos em sistemas de objetos, de práticas e relações, no interior dos quais adquirem seus respectivos significados e funções. 0 marketing etnográfico mapeia a gramática cultural subjacente a diferentes significados, práticas de consumo, de compra e de estilo de vida dos produtos e serviços. 0 consumo é um processo social que começa antes da compra e estende-se até o descarte final da mercadoria.

Um segundo aspecto teórico em relação ao qual o marketing etnográfico destoa das abordagens tradicionais diz respeito à concepção sobrequem éo consumidor. Para o marketing tradicional, ele é um sujeito racional e autônomo que toma decisões individualmente ou, no outro extremo, al guém passível de manipulação, em quem se podem incutir "necessidades e desejos", e que reage de acordo com os estímulos oferecidos pelo mercado. No marketing etnográfico, o consumidor encontra-se em permanente diálogo com a gramática sociocultural que está por trás dos produtos e serviços, tanto para corroborá-la como para rejeitá-la, introduzindo mudanças e inovações.

\section{Quadro: Os princípios centrais do marketing etnográfico}

\begin{tabular}{|l|l|l|}
\hline PRINCÍPIOS & DESCRIÇÃO & AÇõES \\
\hline Produtos e serviços & $\begin{array}{l}\text { Rejeita tratar produtos e serviços como itens isola- } \\
\text { dos sem relacioná-los ao sistema de consumo em } \\
\text { que estão inseridos }\end{array}$ & $\begin{array}{l}\text { Entender o consumo como um processo social } \\
\text { que começa antes da compra e estende-se até } \\
\text { o descarte final da mercadoria }\end{array}$ \\
\hline $\begin{array}{l}\text { Consumidor } \\
\text { cria) de sua história. É alguém em permanente diá- } \\
\text { logo com a gramática sociocultural que está por trás } \\
\text { de produtos e serviços }\end{array}$ & $\begin{array}{l}\text { Ajustar os produtos aos processos de signifi- } \\
\text { cação de vida dos consumidores }\end{array}$ \\
\hline Consumo consumo não é um fim em si mesmo & $\begin{array}{l}\text { Tratar o consumo como um meio, isto é, a ser- } \\
\text { viço dos consumidores enquanto produtores } \\
\text { de significados }\end{array}$ \\
\hline Segmentação de mercado & $\begin{array}{l}\text { Segmenta o mercado em função das concepções so- } \\
\text { bre o mundo e a realidade circundante do indivíduo }\end{array}$ & $\begin{array}{l}\text { Mapear os conjuntos ideológicos e discursivos } \\
\text { que estão por trás dos diferentes sistemas de } \\
\text { consumo }\end{array}$ \\
\hline
\end{tabular}


Um terceiro aspecto relevante diz respeito à visão de que o consumo é um fim em si mesmo. As pessoas adquirem bens e serviços não para tê-los no sentido exclusivo da posse, mas para adquirir por meio deles as propriedades que Ihes são atribuídas: frescor, beleza, praticidade, inovação etc. 0 consumo é sempre um meio. Pode ser a construção de novas identidades, a diferenciação social, a luta por posição social, 0 prazer íntimo, a expressão de visões particulares de mundo, um elemento de resistência cultural e muito mais. 0 conceito de que o consumo seria um fim torna os produtores míopes em relação ao significado e à função de seus produtos em um contexto mais amplo.

Um quarto aspecto relaciona-seà segmentação de mercado. U ma das grandes ambições do marketing é encontrar novas formas de segmentar a população, pois todos são cientes das limitações impostas pela classificação a partir da renda - "estilo de vida" seria uma das classificações possíveis. Entretanto, a metodologia e a teoria permanecem incapazes de abarcar sua natureza complexa. Por meio de pesquisas baseadas em escal as deatitudes eopiniões, podese obter uma grande quantidade de dados referentes à vida cotidiana, às preferências, aos interesses e desejos das pessoas. Como ligar essas informações em um todo coerente que explique por que determinados padrões de consumo e certas práticas encontram-se agrupados em um conjunto de consumidores é o grande problema.

A explicação para essa deficiência encontra-se, em parte, na ausência de uma teoria estrutural do significado. Contudo, ela também pode ser explicada pela idéia de que o consumo é determinado pela disponibilidade financeira das pessoas. 0 total do que se ganha estabelece o limite daquilo que se pode colocar em uma cesta de produtos, mas não indica o que é colocado, nem o porquê. Abordar o consumo pelas limitações da renda significa tentar explicá-lo de dentro, a partir daquilo que as pessoas consomem. Se sabemos que ele é uma atividade mediadora, suas razões encontram-se em seu exterior, em concepções sobre o mundo ea realidade circundante. Em lugar de bater em teclas desgastadas, o marketing deve mapear os conjuntos ideológicos e discursivos que estão por trás dos diferentes sistemas de consumo.
Por fim, se admitirmos que o consumo é uma atividade coerente com as concepções ideológicas das pessoas, poderemos prevê-lo desde que encontremos o foco do qual emana essa coerência. Assim, os esforços deveriam ser centrados na busca das concepções que estruturam a vida das pessoase de como elas afetam o consumo de diferentes produtos e

serviços. Esse procedimento éjustamente o inverso do queé hoje feito pelos pesquisadores do comportamento do consumidor: pesquisa-se o que se consome e não o que nos leva a consumir, ou seja, como o consumo se conecta a outras esferas da vida social.

Da antropologia ao marketing. 0 marketing tem como uma de suas tarefas principais transformar o universo impessoal da produção no mundo personalizado, particularizado e dinâmico do consumo. Portanto, ele lida o tempo todo com processos culturais, eéfundamental que os profissionais estejam cientes deles. 0 marketing etnográfico oferece instrumentos para a compreensão de tais processos culturais. Ele não é um novo tipo de marketing, mas uma nova forma de fazer marketing.

0 que se deseja aqui não é defender o monopólio dos antropólogos na pesquisa do comportamento do consumidor, mas alertar sobre a importância de se observar certos pressupostos metodológicos e teóricos para que a etnografia possa oferecer uma contribuição mais efetiva às pesquisas de marketing.

Lívia Barbosa

Profa. do Departamento de Antropologia da UFF

Pós-doutora pela UNFRJ/PPGAS/Universidade de Tóquio e-mail: livia@visualnet.com.br 